\title{
Investigation into the relationship between the socio-economic and health status of the Coloured people of the Western Cape in an urban setting
}

\author{
EL Stellenberg, D Cur \\ Senior Lecturer, Department of Nursing University of Stellenbosch \\ EB Welmann, DLitt et Phil \\ Professor Department of Nursing, University of Stellenbosch. \\ JC Groenewald, DPhil \\ Professor Department of Sociology, University of Stellenbosch
}

Key Words:

economically active; socio-economic status, health status

\begin{abstract}
Curationis 31(2): 50-59
A descriptive non-experimental approach was applied to investigate and describe the prevalence of factors influencing the health status of the Coloured people of the Western Cape in an urban setting as a dissertation for a doctorate degree. For the purpose of this article the relationship between the socio-economic and health status of the Coloured people of the Western Cape in an urban setting are described. The study only included economically active persons $<21 \leq 50$ years. The objective was to determine the relationship between the health status and the socio-economic status of economically active Coloured people in an urban area as defined. The objectives set for the study were reached through a cross sectional study. The hypothesis, an association between the health status and the socio-economic status of the Coloured people of an urban area in the Western Cape was tested using the chi square statistical test. A purposeful stratified sample of 353 participants was drawn from the residential areas as defined for the purpose of the study. All social classes were well represented in the suburbs. Statistical associations on a $95 \%$ confidence interval were shown between the socio-economic status (i.e. educational level, income and occupation) social habits, diet, and money available for food, exercise and the health status of the respondents. Recommendations were made based on the scientific evidence obtained through the study.
\end{abstract}

Correspondence address:

Dr Ethelwynn Stellenberg,

Department of Nursing

University of Stellenbosch

Tel : (021) 938-9244

Fax :(021)932-6588

Email : elstel@sun.ac.za 


\section{Introduction}

“...A universal understanding exists that moral behaviour in the health arena should strive to allocate medical care justly, endow the patient with autonomy, maximize good effects and minimize bad effects (Kalekin-Fisherman, 1996 :817)". According to Van Niekerk (1993:2) health care is a "... moral command and responsibility". Landman in Van Niekerk (1993:36) argues that appropriate health care is a human right.

The researcher believes that providing appropriate health care is only attainable if preceded by scientific research. The purpose of this study therefore was to investigate the prevalence of factors influencing the health status of the Coloured people of the Western Cape in an urban setting. The researcher believed that several variables that have an influence on an individual's health status are prevalent in this population. Despite the commonality of variables, individual and ethnic differences also exist in the influence of these variables on individuals. The researcher has through her clinical experience identified that a lack of knowledge about the factors influencing the health status of the Coloured population existed. At the time of the research the Coloured populace was the largest population group in the Western Cape. A conspicuous absence of systematic research on the factors influencing the health status of this group, and a corresponding lack of data on adaptive health strategies existed.

However inequalities in health care among population groups existed within the apartheid era, the implications thereof still exist within many population groups. Hirschowitz and de Castro (1998:3) in a national survey of health inequalities in South Africa established that poor health and poverty are closely interlinked. The poor who use public facilities have less access to health-care, in comparison with the more affluent. In this study it was identified that $28 \%$ of Coloured people failed to seek health care of which $47 \%$ could not afford health care and 5\% indicated that they could not afford the transport to the health facility.

This is further illustrated in an outreach project conducted by the researcher among Coloured farm labourers, factors influencing the health status of one hundred farm labourers were determined. All $(100 \%)$ the labourers indicated that the nearest health facility was inaccessible and that they could not afford the transport and medical service. Consequently delayed health seeking behaviour resulted. This was illustrated when the blood pressures of individuals were measured. Blood pressure measurements identified that $50 \%$ of the adults screened were hypertensive and had to be referred to a doctor. Systolic pressure varied between $150-230 \mathrm{mmHg}$ and diastolic between $100-130 \mathrm{mmHg}$.

Similar results were obtained in a second project in which the factors influencing the health status of the participants were determined. Three hundred and twenty (32\%) members of a fishing community of 1000 people were screened. The sample included Coloured people of all social classes. The health status of the people was determined through screening for high-risk behaviours and underlying diseases not known to the individual. Ninety-eight adults of whom $40 \%$ were hypertensive were referred. Ignorance about what health constitutes, how to promote a healthy lifestyle and to contain a disease when identified, was apparent. In both projects, evidence obtained showed that health and illness were not priorities for the participants. Extenuating circumstances encountered by both groups were accessibility, availability, and affordability of health services.

These projects are substantiated in a study conducted within the Bloemfontein region which identified that the Coloured and Black populations experience the most difficult problems with the distance between their residences and service health points in comparison to the White population (Van Vuuren and de Klerk, 1996:21).

Furthermore the inaccessibility of health care may also affect the utilization thereof and has an effect on the health care requirements that manifest themselves. It was identified by Van Vuuren and De Klerk (1996:22) that Black and Coloured respondents reported that they had to wait long hours before they were assisted, while White respondents reported that they were attended without delay.

According to May J, Budlender D, Mokate R, Rogerson C and Stavrou A (1998:1) in a report to the Deputy State President, South Africa is an uppermiddle-income country in per capita terms, but despite this relative wealth, the experience of most South African households is of outright poverty or of continuing vulnerability to being poor. In addition, the distribution of income and wealth in South Africa is among the most unequal in the world, and many households still have unsatisfactory access to education, health care, energy and clean water. It was identified that poverty is not confined to one specific group however $38 \%$ of the Coloureds are poor compared to $5 \%$ of Indians and $1 \%$ of whites.

Already in the early 19th- century an English philosopher, Henry Spencer, issued a stern injunction that preservation of health was not a moral issue but a consequence of economics. The rich were healthier than the poor. This is still very true (Lancet Editorial, 1996:1197).

In South Africa state expenditure on health is showing a gradual decline in the total budget. In 1991/92 the budget for health was $11 \%$, in $1992 / 93=10.8 \%$, in $1993 / 94=10.6 \%$, in $1994 / 95=10.2 \%$ in $1995 /$ $96=10.4 \%$ (RSA Statistics in Brief 1997). “... No amount of juggling by government departments has managed to obscure the overriding correlation between poverty and ill health" (Lancet, 1996:1197). Blackburn (1992:30) concludes that many causes of ill health among low-income people "illustrates that the health of poor families is not within their personal control and is the outcome of low income and poor access to health resources".

A strong correlation also exists between the level of education and standard of living. The poverty rate among people with no education is $69 \%$, compared with $54 \%$ among people with primary education, $24 \%$ among those with secondary education, and $3 \%$ among those with tertiary education (May et al., 1998:5). Hirschowitz and de Castro (1998:3-4) identified that $3 \%$ of the Coloured population have no formal education, $19 \%$ standard 4 or $5,51 \%$ standard 6 to 9 and $13 \%$ matriculated. Only $5 \%$ had higher education. In the same study it was identified that $27 \%$ of the Coloured people are unemployed. Among the employed $69 \%$ are blue collar and $31 \%$ white collar employees. In this study a relationship between unemployment and the health status of individuals were also shown.

According to Bartley (1994:333) there is 
still some controversy over the extent to which excess morbidity and mortality among the unemployed might be a result of those in poorer health being at higher risk of unemployment as well as further at risk of ill health or death. Understanding the relationship between unemployment and ill health and mortality warrants the consideration of four mechanisms, namely the role of relative poverty, social isolation, loss of self-esteem and health related behaviour.

Lahelma E, Rahkonen $\mathrm{O}$ and Huuhka M (1997:795) identified that the unemployed tend to have a poorer health status than their employed counterparts. The unemployed people also tend to be heavier smokers and drinkers (Bartley, 1994:335). According to Clark DO, Patrick DL, Grembowski D and Durham ML (1995:356) socio-economic status is an aspect of the socio-cultural environment that influences health behaviour and health promotion efforts. Low socioeconomic status is associated with a greater frequency of undesirable life events, less effective coping strategies and constrained resources. Consistent global evidence proves that people at a socio-economic disadvantage suffer a heavier burden of illness and have higher mortality rates than their better-off counterparts. Lynch JW, Kaplan GA and Salonen JT (1997:809) indicates that lower socio-economic status is generally associated with higher rates of smoking, obesity, poorer diet habits, lower levels of physical activity and higher prevalence of psychosocial orientations that are related to poor health outcomes. The incidence of smoking is the highest among Coloured people. It was identified that $55 \%$ of Coloureds smoke; $63 \%$ of males and $49 \%$ females smoke. The incidence of alcohol use is $41 \%$ among the Coloured people (Hirschowitz and de Castro, 1998:8-9).

To alter self-efficacy or outcome expectations among low socio-economic status persons, the values and contextspecific constraints will have to be addressed. Those who have limited education regarding factors that predict outcome expectations, require a greater understanding. The predictors of outcome expectations are embedded within social context (Clark et al., 1995). According to Sarnitisart (1994:626) “... health care is a necessity for the rich households while it is a luxury for the poor ..."). In South Africa $23.6 \%$ of all South Africans are members of a medical aid. To analyse this further $81.3 \%$ of all White South Africans do have a medical aid insurance, against $29.9 \%$ of all Coloureds (Savage and Benatar, 1990: 149). A few years later Hirschowitz and de Castro (1998:2) identified that 36\% of Coloured people have a medical aid or medical assurance. It is difficult for individuals without medical aid, which is aggravated further by unemployment and poor access to a health facility to pay for health services. Consequently, delayed health seeking behaviour sets in. This is shown by Hirschowitz and de Castro (1998:4) who identified that $28 \%$ of Coloured people did not seek health care when needed of which $47 \%$ could not afford the care and 5\% could not afford the transport.

The Coloured population is a minority group in South Africa, comprising 8.5\% $(3,508,000)$ of the total population. It has a growth rate of $1.94 \%$. However, Coloured people are concentrated in the Western Cape where this group constitutes $60.8 \%(2,125,000)$ of the total population of the Western Cape, making it the most significant populace in the Western Cape (RSA Statistics in Brief, 1997). Its domination in this Province determines the health status of the Province. By acquiring knowledge about the health status of the population, it is possible for the policy makers in health care to direct their emphasis on health care policies more appropriately. Currently differences in socio-economic and knowledge levels, with existing inequalities in health pose major challenges for the policy makers in health care of this country today and the future.

The lack of knowledge about a healthy lifestyle and low educational levels magnify existing problems. At a time when major budget cuts are being experienced in the health department, the state can least afford problems as described. A high mortality and morbidity rate among the lower socio-economic classes will continue to exist unless a more aggressive approach is applied to preventative and promotive health. Only the introduction of specific long-term interventions will alleviate problems of this nature. Specific programmes must not only aim at changing individual behaviours but also modify the social and physical environment including public policy in support of healthy lifestyles.

It was decided that an investigation into the prevalence of factors influencing the health status of the economically active adults above the age of 21 years and younger or equal to 50 years were to be investigated in a particular urban area. This group contributes significantly towards the economy of the Western Cape. By determining the health status of individuals of this population group, it will reflect the health status of such a group. The health status refers to the health of an individual at a given time.

For this study, an investigation into the prevalence of factors influencing the health status of the Coloured people of the Western Cape in an urban setting was carried out. A study of this nature was not yet undertaken

Against this background this project was undertaken. For the purpose of this article the relationship between the socioeconomic status and the health status will be described.

\section{Objectives}

The following objectives were set:

- $\quad$ To determine the health status of economically active Coloured people in an urban area as defined with specific reference to the indicators as identified by the researcher.

- To determine the relationship between the health status and the socio-economic status of economically active Coloured people in an urban area as defined.

- $\quad$ To make recommendations to the health policy-makers concerning factors influencing the health status of the economically active Coloured people in an urban area as defined and possibly related ethnic groups.

\section{Research design}

A quantitative research design was applied to investigate and describe the prevalence of factors influencing the health status of the Coloured people of the Western Cape in an urban setting. The study was conducted in a descriptive cross-sectional survey, a type of prevalence survey on the lower-lying geographical areas of the Cape. Metropole. It was conducted over a specific time window among individuals in a well-defined population to assess exposure and disease simultaneously. The purpose of this design was to 
provide information about the health experience of the population at a specified time (Hennekens and Burning, 1987:108). As described in Burns and Grove (1993:293) it ensures a description of all the characteristics of a single sample, including a phenomenon of interest and identifying the variables within the phenomenon. The design of the sample maximised the chance that all the social classes were equally represented.

\section{Health status}

Kozier et al. (2000:171) defines health status as the state of health of an individual at a given time. The health status of an individual may also refer to specifics such as pulse rate or temperature. Guided by the ethical committee and promoter the physical health assessment did not include all the body systems but only those which were more commonly affected. A check list of the review of systems included aspects of the following: general health, integumentary, neurological, mouth and throat, breasts (females only), respiratory, cardiovascular, gastrointestinal, urinary. tract, reproductive, joints, endocrine and sleeping disorders. In addition a HealthStyle self-test was completed by each respondent.

Objective test measurements included the following health indicators:

- Diastolic and systolic blood pressure measurements

- Pulse rate

- Respiratory rate

- Blood glucose levels

- Haemoglobin levels

- Blood Cholesterol levels

- Urinalysis for blood, glucose, and protein

- $\quad$ Height and mass measurements

\section{Hypothesis}

Nul hypothesis ( $\mathrm{H} 0$ ) was that there is no association between the health status and the socio-economic status of the Coloured people of an urban area in the Western Cape. The hypothesis ( $\mathrm{H} 1)$ was that there is an association between the health status and the socio-economic status of the Coloured people of an urban area in the Western Cape.

\section{Validity and reliability}

Quantitative research objectivity is an important criterion used to judge the research.
A pilot study was conducted to support the validity and reliability of the study in order to test the instrument for inaccuracies and ambiguity. Furthermore experts in research methodology, statistics and computer science programming evaluated the instrument. A nursing science specialist, a sociologist, and members of the ethical and post-graduate committee evaluated the content of the instrument. Furthermore the validity and reliability was supported by means of a pre-tested health-style self test about behavioural health risks. This self-test was used to cross check the data already obtained about behavioural health risks (National Health Information in Kozier et al., 2000:130-131)

\section{Pilot study}

A pilot study was conducted under similar circumstances as the actual study. The participants that participated in the pilot study were not included in the actual sample of the study. The instrument was tested for ambiguity, inaccuracies and the required corrections were made. A sample of $30(10 \%)$ individuals of the total number of participants of 300 initially planned for the study was included in the pilot study.

\section{Ethical considerations}

Honesty and integrity are vital ethical aspects for any research project (Burns and Grove 1993:89). Ethical considerations for this study were assured by initially obtaining ethical approval for the research from the Ethical committee of the University. Informed consent was obtained from participants, confidentiality and anonymity was assured for all participants. Participants were given the choice of giving written or verbal consent.

\section{Population and sampling}

A purposeful stratified sample of 353 participants was drawn randomly from the residential areas as defined for the purpose of the study. All social classes were well represented in the suburbs. At least fifty participants were drawn from each suburb. Statistically this is the least acceptable number of respondents from a residential area to be used in a sample. The residential areas selected were categorized with the help of town planners of the municipalities concerned into middle-upper socio-economic level, lower socio-economic level (formal housing) and lower socio-economic level (informal housing). According to Krejcie and Morgan (1970:608) a sample of 384 $(0,04 \%)$ participants is required for a population of one million in any scientific study. In this study, a sample of $353(0$, $6 \%$ ) was drawn from a population of 63004 .

A total number of 63004 economically active people live in these suburbs (Census, 1996). The 1996 census data was used as a departure point as these areas are dynamic. Factors contributing to this dynamic state are:

\section{- $\quad$ People are continuously moving in and out of the areas \\ - $\quad$ Rapid growth of informal housing \\ - Housing projects in progress}

The design of the sample maximised the chance that all the social classes were equally represented. The intention was to determine the association between the factors and not to determine the probable size of the different factors in the population.

\section{Criteria, data collection and instrumentation}

A participant who identified him or herself as a Coloured person as classified according to the population register during the apartheid era, $>21$ years $\leq$ $50 y e a r s$, economically active and who gave consent to participate were included in the research study. The economically active target group were chosen as the target group which by definition also include the unemployed individual. These persons potentially contribute to the economy of the province.

The researcher collected the data personally with the help of two trained field workers, (registered nurses) in a structured interview with the use of a structured questionnaire.

Interviews were not always conducted under the ideal clinical circumstances, at times literally in the field, in crowded homes, noisy environments and under verandas. It was out of the control of the researcher to create the "ideal" laboratory for the collection of data. The researcher was dependent on the participants for a particular section of the house where the data could be collected. This was chosen and consented by the participant. The sample included participants living in informal and formal housing structures.

The questionnaire included questions 

education. As the levels of education increased the incidence of highrisk behaviours decreased.

The following associations were found to be statistically significant:

- The association between the level of education and health problems ( $\mathrm{p}=0,037)$.

- The association between the level of education and smoking ( $\mathrm{p}=0,001)$.

- The association between the level of education and consumption of alcohol $(\mathrm{p}=0,030)$.

Figure 3 shows that more u n e m p l o y e d respondents smoke and use alcohol.

It was identified that the association between the

about educational levels, income, occupation, social habits, diet, exercise and a physical health assessment. The objective data about the health status of an individual were obtained through the tests as described.

\section{Data analysis and interpretation of qualitative and quantitative data}

Assisted by a statistician and computer science expert, the researcher used the SAS (Statistical Analysing System) computer programme, to analyse the quantitative data.

The following types of statistical tests were applied in the analysis of the quantitative data:

\section{- Descriptive statistics \\ - Inferential statistics \\ - Chi square test for statistical significance}

The $95 \%$ confidence interval was applied to determine the significance level between the health and socio-economic status of the Coloured people. The confidence interval can provide information about whether a $p$-value is significant or not.

\section{Results}

Figure 1 shows an association between the socio-economic status, social habits and health problems. High-risk behaviours such as smoking and consumption of alcohol are associated with the low socio-economic groups as shown in figure 1 . It was identified in the study that respondents of the lower socio-economic levels practised binge drinking and abused alcohol, while those in the middle-upper levels drank $25-50 \mathrm{ml}$ of alcohol per day.

The association between the socioeconomic level and the use of alcohol was found to be statistically significant $(\mathrm{p}=0,001$

The figure also shows that health problems among respondents of lower socio-economic levels are higher than those among the middle-upper levels.

Figure 2 shows an association between the level of education, social habits and health problems. High-risk behaviours are associated with respondents with low levels of education. Respondents with a grade 11-12 education had less health problems, and the incidence of high risk mass of the respondents and the consumption of beer is statistically significant $(p=0,01)$ and wine $(0,001)$.

The figure also shows that more males smoke and use alcohol than females, the association between gender and the use of alcohol was found to be statistically significant $(\mathrm{p}=0,001$

A decline in the current smokers and the use of alcohol to those who have a history of these social habits could be attributed to the increase in the level of scholastic education as shown in figure 2.

Figure 4 shows the association between education and exercise. Higher levels of education are associated with an increase in the number of respondents who exercise regularly. The importance of exercising are associated with persons of higher education levels.

Figure 5 shows the association between the socio-economic status and exercise. The incidence of exercising among the middle-upper level is higher than that among the lower socio-economic levels. The data of the following associations are of statistical significance:

- The association between exercise and the diastolic blood 
Figure 2 : Showing the association between the level of education, social habits and health problems

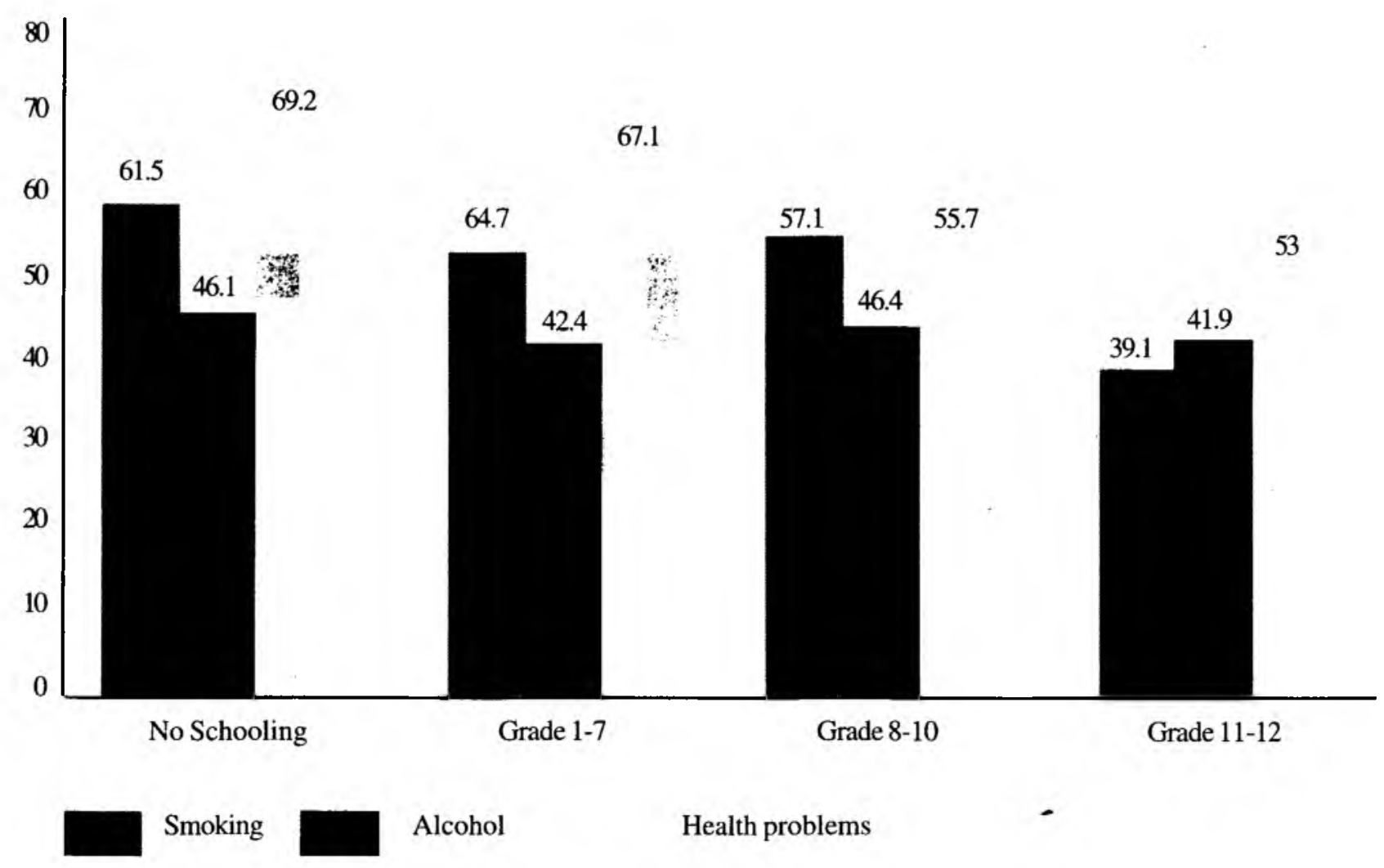

Figure 3 : Showing the association between social habits, gender and employment

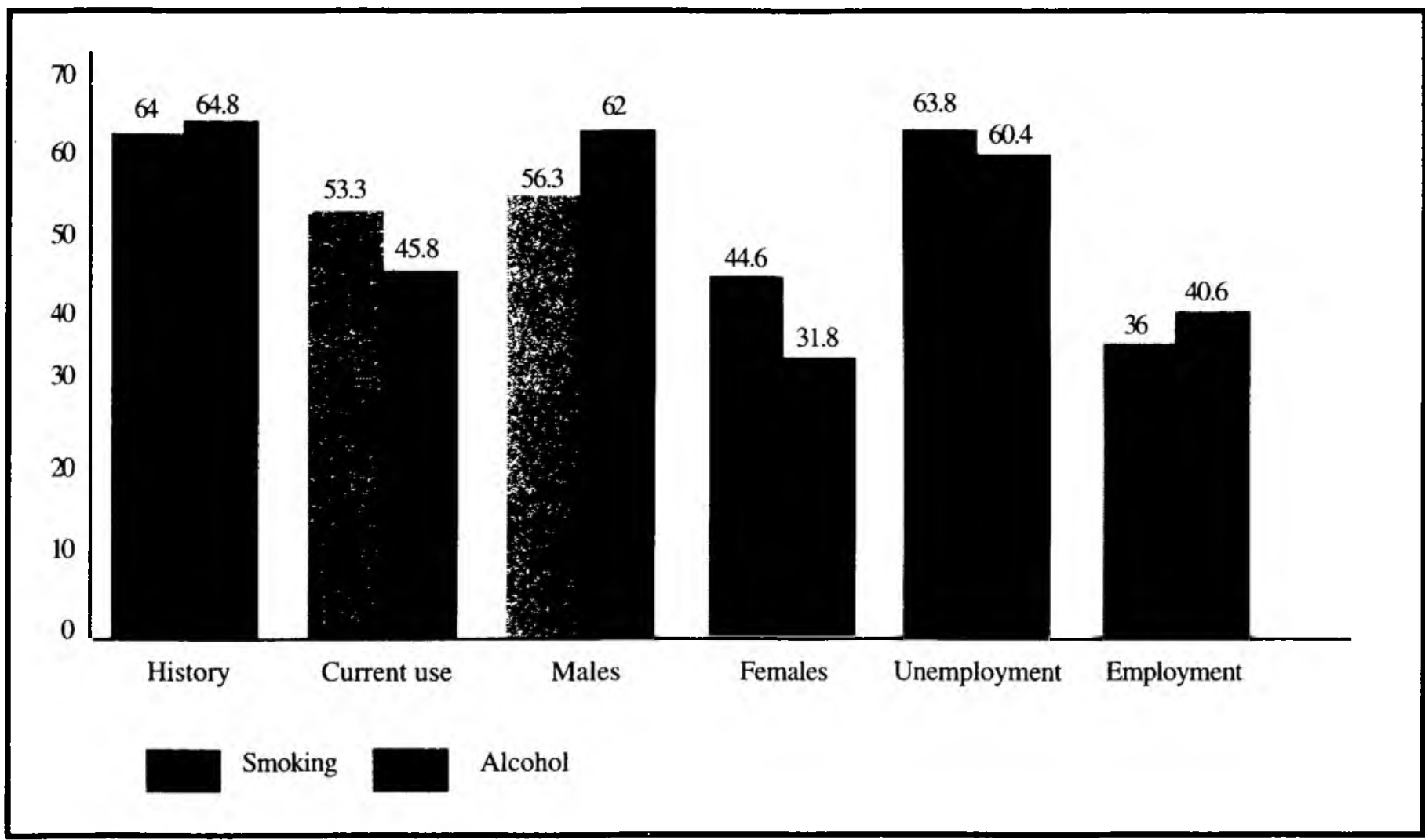

pressure is statistically significant ( $\mathrm{p}=0.02)$

- The association between exercise and the mass of the respondents is statistically

significant $(\mathrm{p}=0.05)$

- The association between

vigorous exercise for $15-30$

55 minutes three times per week and the health problems of respondents is statistically significant $(p=0.04)$. 


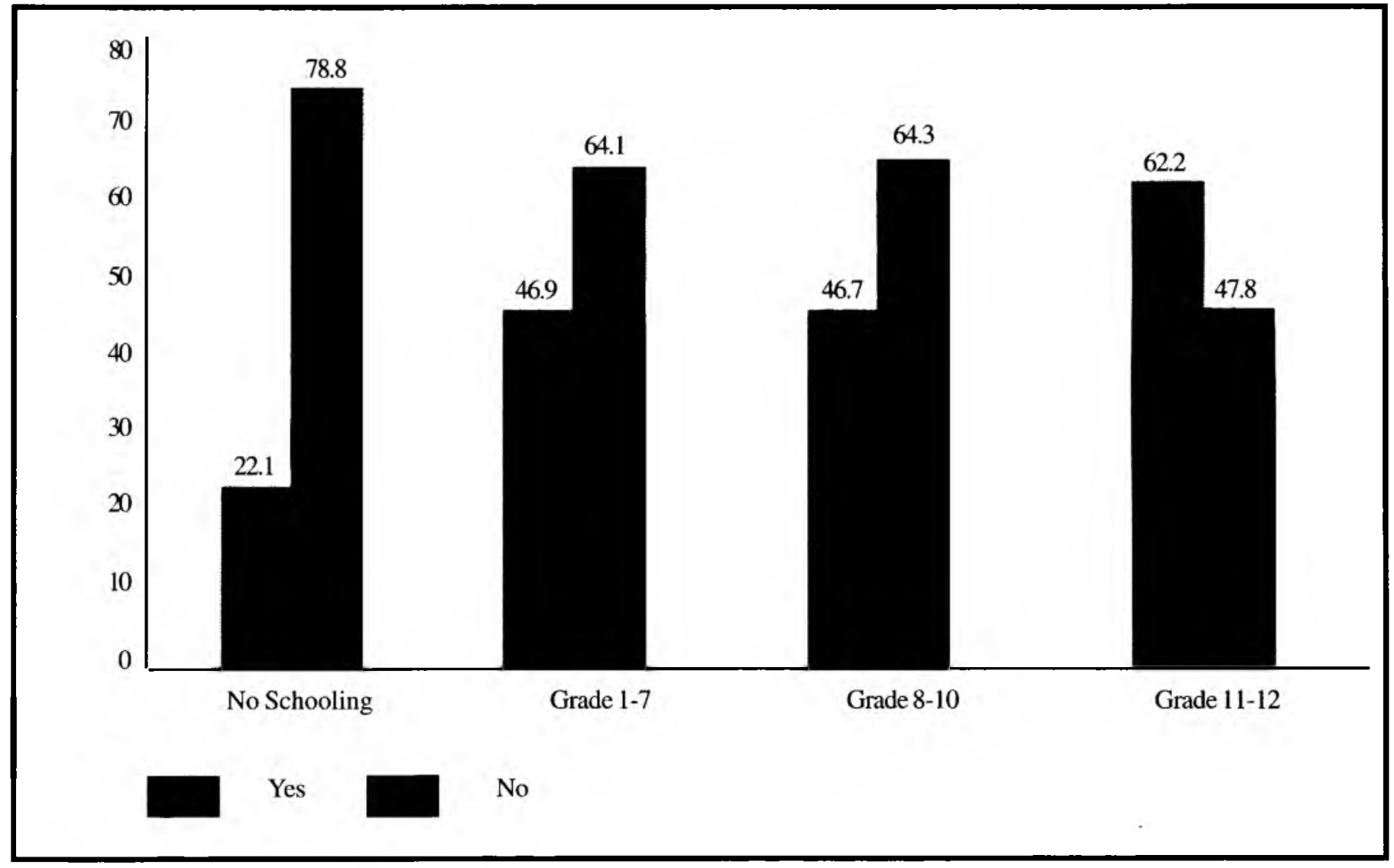

Figure 5 : Showing the association between socio-economic status and exercise

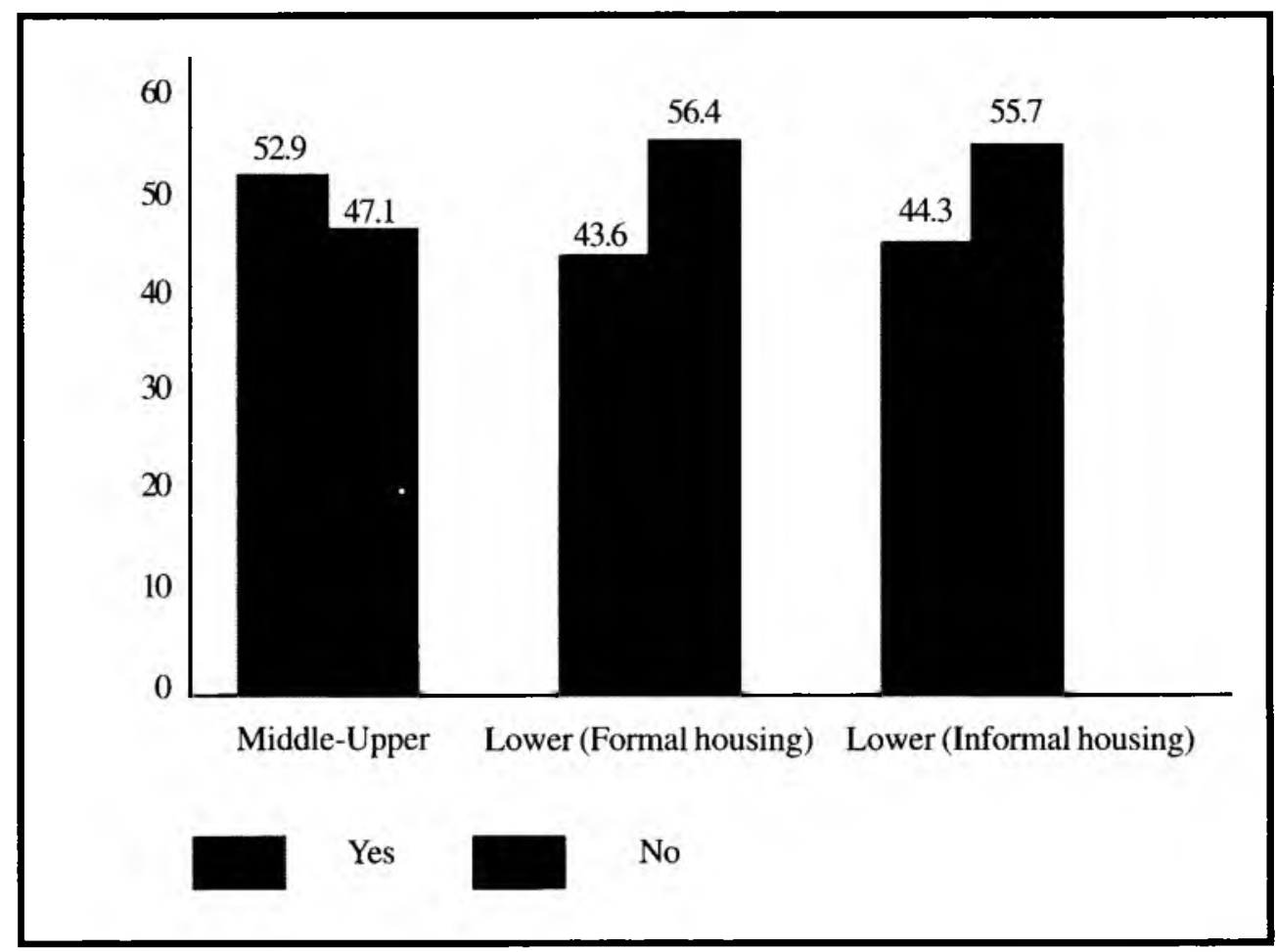

Figure 6 shows the availability of money for meals. The $36 \%$ of respondents always have money for meals, while there are many who indicated that they sometimes have money for meals $(33,7 \%)$ and $7.9 \%$ never have money for meals. The following statistical associations show that:

- The association between the residential area and whether respondents have money to buy food is statistically significant $(\mathrm{p}=0,008)$. The highest incidence of those who do not have money to buy food is from Elsiesriver $(51,3 \%)$ followed by Kraaifontein (49,2\%) and Kuils River (46,0\%).

- The association between the socio-economic level and whether respondents have money to buy food is statistically significant ( $\mathrm{p}=0,001)$. The highest incidence of those who do not have money to buy food is from the lower socio-economic informal level $(69,1 \%)$ followed by the lower socio-economic formal level $(49,6 \%)$.

- The association between the marital status and whether respondents have money to buy food is statistically significant $(\mathrm{p}=0,001)$. The highest incidence of those who do not have money to buy food are living together, $24(70,8 \%)$ followed by the widows/ widowers, $5(70,0 \%)$ and the divorcees, $28(53,6 \%)$.

The association between the literate and whether respondents have money to buy food is statistically significant $(\mathrm{p}=0,001)$. The highest incidence of those who 
Figure 6 : Showing the availibility of money for meals

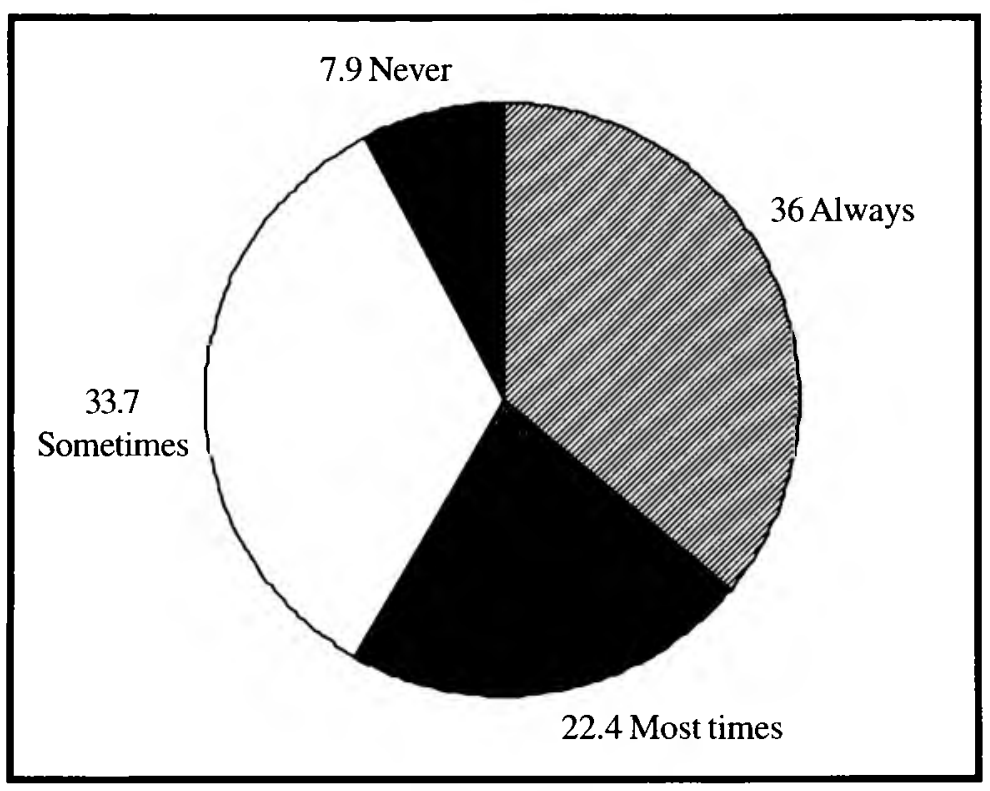

do not have money to buy food are illiterate $(80,0 \%) \mathrm{c}$ omparing to those who are literate $(39,6 \%)$.

Figure 7 shows the association between the socio-economic status and the food variety of respondents per day. $21.8 \%$ and $34 \%$ of the lower socio-economic levels, living in formal housing and informal housing respectively never have a variety of foods per day.

However, ignorance does exist about the composition and importance of a balance diet. The following validates this:

- Only $51.5 \%$ almost always have a variety of foods each day such as fruits, vegetables, lean meats

- $\quad 30.6 \%$ almost never limit the amount of fats and saturated fats

- $\quad 24.6 \%$ almost never avoid salt

- $\quad 37.3 \%$ almost never avoid sugar

- $\quad 55.1 \%$ of the participants were overweight only $35.5 \%$ of normal weight.

\section{Recommendations}

The strengths of a winning nation lie within the citizens of a country as expressed in the old Chinese proverb "When planning for a year, plant corn. When planning for a decade, plant trees. When planning for life, train and educate people".

Training and educating the people of the country will lay the foundation for a successful nation. Despite, the poverty currently experienced in the country, it will gradually give way to a healthy and productive nation if the people are educated and developed.

While the Government of the day is aware of the disparities of the past, there is no short cut to remedying these disparities. A comprehensive approach in development is warranted.

\section{Education and}

\section{development}

Participants with lower levels of education demonstrated higher risk behaviours such as smoking and the abuse of alcohol. By means of education and a $g$ g r e s s i v e development, it may give rise to modification in lifestyle behaviours within individuals. Improving the knowledge about factors influencing the health status of an individual will enable people to become aware of such factors that contribute to a healthy lifestyle. Ultimately selfresponsibility will ensue. This is the health outcome against which the Government should measure its interventions.

\section{Income}

Social development and 
upliftment are imperative and this depends not only on education but also on having employment with an income that will suffice the essential needs of a family.

Job creation should be a priority of both the government and private sector. The majority of the population lives in poverty and social upliftment is essential, in so doing the health status of individuals will improve.

\section{Introduction of a social grant or social coupons to the unemployed}

This recommendation is of fundamental importance, the granting of social grants need to be explored to ensure that grants are used for basic commodities such as food.

According to the Constitution of South Africa (1996:13) everyone has the right to have access to:

(1) Sufficient food and water

(2) Social security, including appropriate social assistance, if they are unable to support themselves and their dependants.

The introduction of such a grant will help to improve the health status of the unemployed, crime may decrease as of the respondents indicated that they are forced to steal in order to survive.

\section{Comprehensive programmes in prevention of disease and promotion of health}

The introduction of comprehensive programmes in prevention of disease and the promotion of health that target all developmental stages are essential. Specific long-term interventions will eliminate problems that influence the health status of the population. Specific programmes must not only aim at changing individual behaviours, but should also modify the social and physical environment including public policy in support of healthy lifestyles.

\section{Continuous research}

In addition, on going research should be implemented through various government departments and universities in order to monitor the government policies that are implemented, the social changes that are being brought about and the effect these have on the health status of the population.

\section{Conclusion}

The hypothesis set for this study was accepted, as an association between the socio-economic and health status of individuals do exist.

According to an Editorial comment in the Lancet (1996:1197) "No amount of juggling by government departments has managed to obscure the overriding correlation between poverty and ill health. A high mortality and morbidity rate among the lower socio-economic people will continue to exist unless more aggressive and constructive measures are introduced". In South Africa as part of the redevelopment policy, programmes have been introduced such as the free health service. However, this is not a solution in assisting the people of lower socio-economic levels, as recommended educating and developing the people, creating jobs, preventing disease and promoting good health is the core of redevelopment. Aggressive and constructive measures will ensure a healthy nation and economy.

\section{References}

BARTLEY, M 1994: Unemployment and ill health: understanding the relationship. Journal of Epidemiology and Community Health 48, 1998: 333-37.

BLACKBURN, C 1992: Poverty and health: working with families. Philadelphia: Open University Press.

BURNS, N \& GROVE, SK 1993: The Practice of Nursing Research. Conduct, Critique \& Utilization. Second Edition. Philadelphia, Pennsylvania: WB Saunders Company.

CLARK, DO; PATRICK, DL; GREMBOWSKI, D \& DURHAM, ML 1995: Socioeconomic Status and Exercise Self-Efficacy in Late life. Journal of Behavioral Medicine 18(4) 1995 March 17:356-76.

SOUTH AFRICA (REPUBLIC) 1996: Constitution Act (Act 108 of 1996), Pretoria: Government Printer.

EDITORIAL 1996: Is health a moral responsibility? The Lancet 347(9010), May 1996:1197.

HENNEKENS, CH \& BURNING, JE 1987: Epidemiology in Medicine. First Edition. Boston, Little, Brown and Company.
HIRSCHOWITZ, R \& DE CASTRO,J

1998: A National Household Survey of Health Inequalities in South Africa. Case Survey for Kaiser Family Foundation. Chapter 5. Background Information: Adults Aged 16 to 64 Years. August 1998: http://www.hst.org.za/case/chapt 5.htm

HIRSCHOWITZ, R \& DE CASTRO,J 1998: A National Household Survey of Health Inequalities in South Africa. Case Survey for Kaiser Family Foundation. Chapter 6.Access to Health-Care: Adults Aged 16 to 64 Years. August 1998: http:/ /www.hst.org.za/case/chapt 6.htm

KOZIER, B; ERB, G \& BERMAN, AJ 2000: Fundamentals of Nursing. Concepts Process and Practice. Fifth Edition. California: Addison \& Wesley School Division, Benjamin / Cummings Publishing Company.

KREJCIE, RV \& MORGAN, DW 1970: Determining Sample Size for Research Activities. Educational and Psvchological Measurements 30. Autumn 1970:608.

LAHELMA, E; RAHKONEN, O \& HUUHKA, M 1997: Changes In The Social Patterning Of Health? the Case Of Finland 1986-1994. Social Science Medicine 44(6) 1997:789-99.

LANDMAN, WA 1993: Appropriate health care as a human right: a philosophical perspective. (In: Van Niekerk A, Ed. Health Care As Human Right. Stellenbosch: Unit For Bioethics, p36).

LYNCH, JW; KAPLAN, GA \& SALONEN, JT 1997: Why Do Poor People Behave Poorly? Variation in Adult Health Behaviours And Psychosocial Characteristics by stages of The Socioeconomic Life Course. Social Science Medicine. 44(6) March 1997:809819.

MAY,J; BUDLENDER,D; MOKATE, R: ROGERSON, C \& STAVROU,A 1998: Poverty and Inequality in South Africa. 8 September 2000. http://www.polity.org.za / govdocs /reports / poverty.html

\section{NATIONAL HEALTH INFORMATION} CLEARINGHOUSE, WASHINGTON DC Health-style self-test. (In Kozier B, Erb G and Berman AJ 2000: Fundamentals of Nursing. Concepts Process and Practice. Fifth Edition. California: 
Addison \& Wesley School Division, Benjamin / Cummings Publishing Company, 130-131).

SARNTISART, I 1994: Poverty, Income, Inequality and Health Care Consumption in Thialand. Southeast Asian Journal Tropical Medicine Public Health 25(4), December 1994:618-627.

SAVAGE, M \& BENATAR, S 1990: An analysis of health and health services. (In. Schrire R Ed. 1990: Critical choices for South Africa. Cape Town, Oxford University Press, 147-167).

STATISTICS IN BRIEF 1997: Central Statistical Service Department, Republic of South Africa.

STATISTICS SOUTH AFRICA 1996: South Africa Census. Cape Town.

VAN NIEKERK, A 1993: Introduction: Health care, Ethics and Human Rights in South Africa. (In Van Niekerk. AED. 1993 : Health Care As Human Right. Stellenbosch: Unit for Bioethics, University Of Stellenbosch p2).

STELLENBERG, EL 2000: An Investigation into the Factors Influencing the Health Status of the Coloured People of the Western Cape in an Urban Setting. University of Stellenbosch (D-Cur Dissertation).

VAN VUUREN, SJE \& de KLERK, GW 1996: Accessibility of Professional Health Care (PRCH) in Greater Bloemfontein. Curationis 19(2) December 1996:19-24. 